\title{
FORMAÇÃO INICIAL DE PROFESSORES DE FÍSICA: A QUESTÃO DA INCLUSÃO DE ALUNOS COM DEFICIÊNCIAS VISUAIS NO ENSINO REGULAR
}

\author{
Early Training of Physics Teachers: the question \\ of inclusion of students with visual impairments \\ in mainstream education
}

Maria da Conceição Barbosa Lima ${ }^{1}$. Giselle Faur de Castro $^{2}$

Resumo: A partir de inquietações a respeito de alunos deficientes visuais em salas de aula regulares de Física, surgiu a necessidade de se questionarem os futuros professores acerca do assunto em uma disciplina ministrada no período 2009/2 para alunos de licenciatura em Física. O objetivo foi perceber as evoluções apontadas pelos futuros docentes frente ao tema de inclusão de alunos com Deficiência Visual a partir de suas próprias reflexões sobre os debates gerados em aula. Para a coleta de informações, usamos quatro documentos escritos de três alunos que concluíram a disciplina: o questionário respondido no primeiro dia de aula; os "diários de bordo"; os trabalhos finais; e a avaliação do curso. A análise dos dados foi baseada na análise de discurso bakhtiniana. Notamos que os alunos evoluem em suas ideias sobre inclusão, se sensibilizam para as aulas com melhores adequações para deficientes visuais e se propõem a serem professores inclusivos.

Palavras-chave: Inclusão. Deficiência visual. Análise de discurso. Formação inicial.

\begin{abstract}
From concerns about students with visual impairments in regular classrooms for Physics, arose the necessity to question future teachers about this subject in a course: "Teaching Physics and Social Inclusion", taught in the 2009 second semester, for undergraduate students in Physics. The objective was to perceive the trends suggested by the future teachers, from their own reflections on the debates which emerged in class, about inclusion of visually impaired students. Information was collected from written material among three students who had already completed the course: a questionnaire answered in the first class, a kind of log-book of the class, students' final projects and their course evaluations. Data analysis was based on the Bakhtinian Analysis of Discourse. We noted that the students evolve in their ideas about inclusion, being more sensitive towards the subject, developing more suitable solutions for those with visual disabilities and that they intend to be more inclusive professionals.
\end{abstract}

Keywords: Inclusion. Visual impairment. Discourse analysis. Training.

\footnotetext{
${ }^{1}$ Departamento de Física Aplicada e Termodinâmica, Instituto de Física Armando Dias Tavares, Universidade do Estado do Rio de Janeiro. Rua São Francisco Xavier, 524, $3^{\circ}$ andar. Maracanã, Rio de Janeiro, RJ, Brasil. 20.550-900.mcablima@uol.com.br

${ }^{2}$ Escola de Educação, Ciências, Letras, Artes e Humanidades, Universidade UNIGRANRIO. Rio de Janeiro, RJ, Brasil. Bolsista CNPq.
} 


\section{Introdução}

Privar qualquer pessoa de conhecer e buscar conhecimento é impedir o seu crescimento e a sua formação. Por isso, é importante ressaltar que ensinar física para alunos videntes e não videntes, de maneira inclusiva, é promover não só inclusão, igualdade de oportunidades e educação científica, mas também permitir o desenvolvimento de criticidade e de cidadania: a inclusão, feita de maneira adequada, melhora a aprendizagem de todos os alunos, gerando qualidade de vida.

A partir de inquietações e questionamentos a respeito de alunos deficientes visuais em salas de aula regulares de física, surge a necessidade de se questionar os futuros professores acerca da inclusão desses alunos, para analisar o que eles pensam sobre a rotina de sala de aula e que estratégias estão construindo, ao longo da graduação, para superar as possíveis barreiras que surgirão. O que pensam os futuros professores a respeito do tema "inclusão de alunos deficientes visuais em salas de aula regulares de física"? Que estratégias devem ser construídas durante a graduação para favorecer futuramente a efetivação de práticas inclusivas?

Para responder a essas perguntas, nos propomos a analisar quatro fontes de informações de uma disciplina - "Ensino de Física e Inclusão Social" -, ministrada no período de 2009/2 para alunos de licenciatura em Física em nosso Instituto: um questionário respondido no primeiro dia de aula sobre o tema; os "diários de bordo"; os trabalhos finais; e a avaliação da disciplina feita no último dia de aula. O objetivo é perceber as evoluções apontadas pelos futuros docentes frente ao tema de inclusão de alunos com deficiência visual (DV) em salas de aula de física a partir de suas próprias reflexões sobre os debates gerados em aula.

Para a coleta de informações utilizaremos os documentos escritos de três alunos que concluíram a disciplina, apesar de existirem, inicialmente, nove alunos matriculados. A análise dos dados será baseada na análise de discurso bakhtiniana.

Pensamos que, com essa pesquisa, a disciplina, que ainda é eletiva no curso em questão, possa ser repensada e reestruturada com o objetivo de se tornar uma disciplina obrigatória.

\section{Referencial teórico}

O tema da inclusão social vem ganhando cada vez mais destaque na área da pesquisa em Educação e em Educação em Ciências, e, também, junto aos educadores que estão em sala de aula e se deparam todos os dias com as questões acerca do tema proposto (SILVA, 2009).

Para analisar os obstáculos a serem superados pelo professor de Física na rotina de sala de aula com alunos deficientes visuais, é preciso levar em consideração que ele deve, segundo a LDB, propiciar: “[...] preparação básica para o trabalho e a cidadania do educando, para continuar aprendendo, de modo a ser capaz de se adaptar com flexibilidade a novas condições de ocupação ou aperfeiçoamento posteriores" (BRASIL, 1996, p. 15).

Laplane e Batista (2008) chamam atenção para questões importantes: De que modo a deficiência visual interfere no desenvolvimento e na aprendizagem? Como ensinar alunos com deficiência visual? Qual é o lugar dos recursos pedagógicos e dos auxílios na sala de aula? Como escolher o recurso indicado para cada situação? Estas autoras dizem que, para responder a essas perguntas, é importante compreender que "a deficiência visual engloba uma varie- 
dade de condições orgânicas e sensoriais que têm consequências diferentes no desempenho visual dos sujeitos" (LAPLANE; BATISTA, 2008, p. 210). Relatam ainda que a deficiência visual é caracterizada desde pequenas alterações na acuidade visual até a total ausência de percepção de luz, sendo baixa visão e cegueira as que trazem mais implicações para a vida dos deficientes visuais.

Por isso, é fundamental questionar os futuros professores acerca da inclusão de alunos deficientes visuais em salas de aula de Física para analisar não somente as suas concepções sobre a temática, como também pensar em estratégias para formar professores inclusivos, preocupados com a formação de seus alunos videntes e deficientes visuais.

\section{Educação inclusiva}

A partir de tais inquietações e questionamentos a respeito de alunos deficientes visuais em salas de aula regulares de física, surge a necessidade de se definir educação inclusiva a fim de que tal processo ocorra efetivamente. Pacheco, Eggertsdóttir e Marinósson (2007) chamam a atenção que o termo "educação inclusiva" está relacionado à tentativa de atender à diversidade das necessidades de tais alunos, e ressaltam que um sistema educacional que se destina a fornecer a inclusão efetiva e total baseia-se nos seguintes princípios:

Todas as crianças ${ }^{3}$ conseguem aprender; todas as crianças frequentam classes regulares adequadas à sua idade em suas escolas locais, [...] recebem programas educativos adequados, [...] recebem um currículo relevante às suas necessidades, [...] participam de atividades co-curriculares e extracurriculares, [e] beneficiam-se da cooperação e da colaboração entre seus lares, sua escola e sua comunidade. (BRUNSWICK, 1994, apud PACHECO; EGGERTSDÓTTIR; MARINÓSSON, 2007, p. 14)

Vale ressaltar que práticas inclusivas precisam estar embasadas em abordagens mais diversificadas, flexíveis e colaborativas a fim de que todos possam participar do processo de ensino-aprendizagem. Pacheco, Eggertsdóttir e Marinósson (2007) ressaltam ainda a diferença entre inclusão e integração: uma escola que visa à inclusão deve buscar estratégias para se ajustar a todos os seus alunos, e não esperar que o deficiente, seja ele visual ou de qualquer outro sentido, se ajuste à escola, ou seja, que ele se integre ao que já existe.

Nesse mesmo sentido, e baseadas na lógica inclusiva, Anjos, Andrade e Pereira (2009, p. 117) trazem que "em vez de serem envidados esforços para fornecer à pessoa condições de adaptar-se à escola, procurar-se-ia construir uma escola para atender às pessoas concretas que fazem parte dela". Além disso, apontam que:

${ }^{3}$ Nós incluímos, aí, adolescentes, jovens e adultos. Nota nossa. 
[...] a atuação conjunta de pessoas que vivem diferentemente o acesso ao conhecimento deveria contagiar o coletivo, abrindo novas experiências curriculares, flexibilizando a grade de disciplinas e a estrutura de séries; enfim, criando novas lógicas no interior da escola e nas relações educativas como um todo. (ANJOS; ANDRADE; PEREIRA, 2009, p. 117)

Podemos enfatizar que a ideia é perceber que a escola e o professor precisam encontrar estratégias para favorecer a participação dos alunos com deficiência visual nas aulas, no nosso caso de física, construindo práticas inclusivas.

Dessa maneira, todos têm o direito de participar ativamente da construção do próprio conhecimento, uma vez que é através dele que é possível encontrar caminhos para saborear o mundo que nos rodeia. Privar qualquer pessoa de conhecer e buscar esse conhecimento é impedir o seu crescimento e a sua formação.

Por isso, é importante ressaltar que ensinar física para alunos videntes e não videntes, de maneira inclusiva, é promover não só inclusão, igualdade de oportunidades e educação científica, estimulando a criticidade e a cidadania: a inclusão, feita de maneira adequada, melhora a aprendizagem de todos os alunos, gerando qualidade de vida. Além disso, podemos entender que os professores também passam por processos de reflexão a partir das práticas inclusivas acerca de seus conhecimentos científicos, uma vez que têm de adequá-los de maneira mais detalhada, utilizando não só os habituais recursos visuais a que estão acostumados, mas, também, percebendo novas perspectivas sobre o ensino e sobre a aprendizagem.

\section{Formação inicial}

As discussões realizadas até aqui remetem a um indispensável ponto: a formação dos futuros professores. Nesse sentido, Camargo e Nardi (2007, p. 380) apontam para a seguinte questão: "como incluir alunos com deficiências na rede regular de ensino, sem o devido preparo dos professores que irão recebê-los?".

Segundo a Declaração de Salamanca sobre princípios, políticas e práticas na área das necessidades educativas especiais (1994, p. 11):

Treinamento especializado em educação especial que leve às qualificações profissionais deveria normalmente ser integrado com ou precedido de treinamento e experiência como uma forma regular de educação de professores para que a complementaridade e a mobilidade sejam asseguradas.

Assim, torna-se fundamental envolver a formação inicial de professores de física ao se tratar do tema da inclusão de alunos com deficiências visuais no ensino regular. E este foi o motivo primeiro da criação dessa disciplina. 


\section{Metodologia}

Entendemos por metodologia "o caminho do pensamento e a prática exercida na abordagem da realidade" (MINAYO, 1994, p. 16).

Uma vez que iremos interpretar o discurso escrito de licenciandos, o caráter complexo e subjetivo dos dados requer uma linha qualitativa de pesquisa, ou seja, "uma metodologia de investigação que respeite sua natureza” (PÉREZ GÓMEZ, 1998, p. 99).

Ao contrário do enfoque positivista, que defende uma concepção relativamente estática da realidade social, à imagem e semelhança da realidade física, no enfoque interpretativo considera-se que a realidade social tem uma natureza constituída radicalmente diferente da realidade natural. O mundo social não é fixo, nem estável, mas dinâmico e mutante devido ao seu caráter inacabado e construtivo. (PÉREZ GÓMEZ, 1998, p. 100)

Esse caráter inacabado e construtivo - do mundo, da reflexão do mundo e da prática docente - nos remete à abordagem que Mikhail Bakhtin faz da construção do ser (BRAIT, 2006). Acreditamos, assim, que a utilização desse referencial possibilitará uma análise mais coerente do fenômeno analisado admitindo-se que existem múltiplas realidades de acordo com a sua construção.

Nossa pesquisa se caracteriza como uma pesquisa intervenção que, de acordo com Maraschin (2004, p. 98), "constitui-se como inovação ao propor perspectivas metodológicas de ação capazes de sustentar trabalhos de intervenção para além da pesquisa propriamente dita". A dinâmica da pesquisa intervenção se adequou perfeitamente aos nossos objetivos, uma vez que a professora do curso interveio em diversos momentos. Segundo Maraschin (2004, p. 105),

O pesquisar torna-se ele mesmo inovação, no momento que constitui um outro domínio de ação (outra comunidade de observadores), pautadas no explicar, no qual é afirmada a possibilidade de conhecer, compreender e transformar, ou não, as congruências que configuram os próprios modos de explicar o viver posto em questão.

\section{Nossos sujeitos}

Para alcançar os objetivos, escolhemos três licenciandos que cursaram, no último período (2009/2), a disciplina "Ensino de física e inclusão social". A escolha destes três sujeitos tem um motivo justificável: as turmas de licenciatura, em geral, mesmo nas disciplinas obrigatórias, são pequenas, decrescendo este número de inscritos quando se trata de eletivas. Sendo assim, Ensino de física e inclusão social, naquele ano, contou com nove alunos inscritos, sendo que quatro não entregaram o diário de bordo, ficando automaticamente fora da pesquisa por não oferecimento de dados, e dois foram reprovados. Desta forma, ficamos com 
os cinco restantes, divididos em duas moças e três rapazes. Mas, destes, um entregou-o incompleto e o outro não o fez, como prescreve Zabalza (2002, p. 16):

Escrever seu próprio diário é a experiência de contar (o que você mesmo faz) e de contar-se a si mesmo (como um duplo ator: o ator que realiza as coisas contadas e o ator que as conta). Experiência narrativa que posteriormente tornará possível uma nova experiência, a de ler-se a si mesmo com atitude benévola ou crítica, mas tendo a oportunidade de reconstruir o que foi a atividade desenvolvida e nossa forma pessoal de vivê-la.

Desta maneira, passamos a contar com três diários de bordo. Os de M., V. e J. Um rapaz e duas moças, que entraram na universidade por vestibular. As moças entraram no ano de 2003, o que demonstra que estão atrasadas em seus cursos, e o rapaz em 2006, indicando um ano de atraso em relação ao tempo de conclusão do curso.

Além da disciplina em questão, cursavam, em média, nove disciplinas, sendo a maioria obrigatória, divididas entre o Instituto de Física e a Faculdade de Educação.

\section{Instrumentos}

Utilizamos as quatro fontes de informações já citadas anteriormente: o questionário sobre o tema respondido no primeiro dia de aula; os "diários de bordo"; os trabalhos finais; e a avaliação da disciplina feita no último dia de aula pelos sujeitos. Dessas informações, selecionamos os dados que serão analisados.

A análise baseou-se na análise de discurso bakhtiniana. Em função do quadro teórico-metodológico escolhido para a pesquisa, organizamos os dados coletados, partindo das cadeias enunciativas construídas pelos futuros professores.

\section{Análises}

\section{O questionário}

A proposta deste questionário foi conhecer os motivos que levaram os estudantes a se inscreverem nesta disciplina, o que pensam sobre inclusão, quais suas expectativas sobre o curso e quais, como e com quem eles obtiveram alguma informação sobre ela. Além, naturalmente, de algumas informações pessoais. É importante ressaltar que este questionário foi aplicado logo no primeiro encontro entre a professora e a turma. Os dados referentes à identificação pessoal e identificação acadêmica foram utilizados como dados dos sujeitos na seção metodologia. 


\section{Descrição das respostas}

Como resposta à pergunta inicial do questionário, "o que esperavam da disciplina?", M. respondeu que esperava ter uma visão sobre as necessidades especiais e como tratar seus portadores caso houvesse necessidade. V. afirmou que desejava aprender mais sobre o tema, enquanto J. disse que esperava obter conhecimentos que a auxiliassem a ser uma professora de física que conseguisse lidar com todos os tipos de alunos, inclusive os especiais.

Questionados sobre como caracterizariam portadores de necessidades especiais, a partir de uma lista, M. respondeu que alunos com necessidades especiais são aqueles com problemas psicomotores, sensoriais e que sofrem de síndromes mentais, não sabendo o que faria se algum deles viesse a ser seu aluno. De acordo com este estudante, todos os alunos caracterizados por ele como portadores de necessidades especiais teriam condições de aprender física, com exceção dos que apresentam paralisia cerebral e síndromes mentais. Já V., quando foi solicitada a marcar as necessidades especiais, não conseguiu defini-las nem agrupá-las, marcando todos os deficientes sensoriais, porém evitando marcar os deficientes sociais e econômicos em sua totalidade. Para esta aluna, qualquer pessoa pode aprender física, em suas palavras, "como a física estuda os fenômenos da natureza, qualquer pessoa que vive no mundo e sente a natureza pode aprender física". E para J., só são necessitados especiais os deficientes sensoriais, os que apresentam dificuldade de aprendizagem e os que têm síndromes mentais, tendo condições de aprender física todos aqueles que ela marcou como necessitados especiais, ou seja, os que têm dificuldade de aprendizagem, os surdos e deficientes auditivos, os deficientes visuais e os que apresentam síndromes mentais.

Solicitados a responderem o que fariam caso encontrassem, em suas futuras turmas, alguém com necessidades especiais, deram as seguintes respostas: M. foi categórico e respondeu que não saberia. V. também não saberia, mas iria recorrer a professores mais experientes e pesquisaria alguns métodos de ensino, e, por fim, J. afirmou que procuraria encontrar meios para que estes alunos participassem das aulas.

Quanto às aulas, tanto experimentais quanto teóricas, para M., todos têm condições de assisti-las e as dificuldades seriam reforçadas pelas particularidades de cada um. As dificuldades, para ele, seriam: abstração, compreensão e visualização. Quanto à facilidade de assistir a aulas de física, V. afirmou que o professor deve investir em situações que utilizem os sentidos não afetados pela deficiência, chamando a atenção para a importância do emprego de uma linguagem adequada durante as aulas. Para J., todos os alunos necessitados especiais marcados por ela têm condições de acompanhar as aulas de física, sejam elas experimentais ou teóricas. Quanto às dificuldades apresentadas, seria preciso pensar em experimentos adequados e no uso de material didático correto para as teóricas.

Perguntado sobre o que era inclusão, M. respondeu: "Inclusão é adaptar as aulas às necessidades especiais das pessoas, evitando a exclusão". Para V., inclusão é: "[...] fazerparte de algum lugar ou de algo. Se você está na escola deve sentir-se parte dela e colaborando com ela.". Quanto à inclusão, J. respondeu: "É englobar num certo 'conjunto' elementos que não fazem parte do mesmo". 


\section{Análise das respostas}

Analisando as respostas de M., notamos que ele sabe o que significa inclusão, mas não aplica tal conhecimento em suas respostas anteriores para tratar das dificuldades de alunos deficientes em aulas de física, teóricas ou experimentais. Podemos destacar ainda que, na resposta à pergunta sobre as dificuldades de alunos em acompanhar aulas experimentais, há uma incoerência entre sua ideia e a de Éder Pires de Camargo (2008) acerca da abstração de tais alunos. Por fim, vale a pena apontar que a leitura de suas respostas indica que M. fez uma leitura prévia de todo o questionário antes de respondê-lo.

A última pergunta feita a $\mathrm{V}$. nos permite notar que, mesmo não conhecendo uma definição pronta sobre inclusão social, como apontada por M., ela consegue, com suas próprias ideias, desenvolver uma resposta adequada sobre o tema. Além disso, podemos destacar que suas respostas são coerentes com tal visão, uma vez que desenvolve estratégias para que a inclusão realmente ocorra. É importante identificar sua postura de futura professora diante do desafio de lecionar para uma turma inclusiva. V. se coloca como protagonista do processo de inclusão ao enfatizar que é dever do professor preparar as aulas, teóricas e experimentais, pensando nas necessidades especiais de cada aluno e em linguagens diferenciadas para cada aula. Devemos ressaltar ainda que, como respostas ao questionário do primeiro encontro da turma, V. já imaginava que teria dificuldades em pensar na preparação de aulas inclusivas. Mesmo assim, aprofunda mais as ideias sobre aulas inclusivas do que M. em suas respostas e justificativas para as perguntas feitas.

Quanto a J., notamos, na análise de seu questionário, o não-oferecimento de respostas aprofundadas para as perguntas feitas, o que era esperado para o primeiro contato com o tema em questão. Pela resposta à última pergunta, percebemos que J. não conhece a diferença entre inclusão e integração. Porém, ao tratar das dificuldades de alunos deficientes em aulas de física, teóricas e experimentais, ela aponta que as estratégias devem sofrer adequações pensando nesses alunos.

\section{Os diários de bordo ${ }^{4}$}

A análise dos diários será feita por meio das respostas dos licenciandos, que serão consideradas como enunciados bakhtinianos, com eles foram construídos os Episódios. Essa ideia de episódios se refere aos segmentos do discurso que têm fronteiras claras em termos de conteúdo semântico referencial ou de tarefas que são aí desenvolvidas (MORTIMER et al., 2005 apud CASTRO, 2009), visto que cada um dos sujeitos deu maior relevância a um determinado aspecto da aula.

\footnotetext{
${ }^{4}$ As transcrições foram realizadas sem qualquer modificação nas palavras dos alunos, assim sendo, eventuais erros de português são de responsabilidade de cada um deles. 
Formação inicial de professores de Física: ...

\section{Caracterizações gerais}

O diário de M. traz muitas reflexões acerca dos temas trabalhados em aula, contribuindo, ainda, com críticas e sugestões para possíveis mudanças na disciplina. Isso demonstra autonomia e certo domínio do que foi estudado. Relata comentários sobre os outros alunos da disciplina. O diário traz, também, os trabalhos feitos por ele e pelos outros alunos. M. enfatiza a diferença entre integração e inclusão. $\mathrm{O}$ de $\mathrm{V}$. descreve as aulas detalhadamente sem reflexão, relatando todos os textos trabalhados em aula. Podemos ressaltar a ênfase na diferença entre integração e inclusão. O de J. é um diário bastante descritivo, no qual ela se coloca no lugar do outro, caracterizando uma dimensão emocional. Além disso, traz uma experiência pessoal, e seu discurso é marcado por questionamentos ao longo de suas reflexões.

\section{Análise dos episódios}

A escolha dos episódios foi feita com base nas ideias recorrentes contidas em, pelo menos, dois diários. Assim, identificamos nove trechos que geraram quatro episódios.

Para analisar os episódios, precisamos lembrar que M., V. e J. cursaram a mesma disciplina e estudaram os mesmos textos. Portanto, apesar de interpretações diferentes dadas às mesmas ideias devido à individualidade de cada sujeito (BAKHTIN, 1997), vamos entender que eles partem de um mesmo referencial: “[...] mas a utilização da palavra na comunicação verbal ativa é sempre marcada pela individualidade e pelo contexto. [...] pois, na medida em que uso essa palavra numa determinada situação, com uma intenção discursiva, ela já se impregnou de minha expressividade" (BAKHTIN, 1997, p. 313).

Percebemos, nos trechos abaixo, ideias sobre a capacidade de aprendizagem de alunos videntes e deficientes visuais:

[...] Pra mim eles tem total igualdade no processo de abstração de um fenômeno físico, que não necessita da visão clara, como, por exemplo, o mundo microscópico, a dificuldade é a mesma pros dois. (M.)

[...] Fica claro que aluno é sempre aluno, não depende de ser ou não deficiente, não há percepsões alternativas divergentes dos alunos videntes. (V.)

Os dois licenciandos consideram que os alunos deficientes visuais possuem a mesma capacidade de aprender que os alunos videntes. Sendo que V. chega a afirmar que as percepções alternativas são as mesmas, o que deve ter sido marcado pelo discurso de Camargo (2008), indicando certa polifonia (a convivência de uma multiplicidade de vozes que interagem ou interagiram um dia) em seu discurso:

Como apontam várias pesquisas nesta área, tais tendências também são verificadas junto a pessoas videntes, e, portanto, indivíduos cegos não representam exceção à maneira alternativa de se abordar questões relacionadas ao referido tema \{concepções alternativas\}. (CAMARGO, 2008, p. 70, grifo nosso) 
Os trechos a seguir dizem respeito à necessidade de se ouvir a fala dos cegos:

[...] Acredito que até então foi o texto mais interessante e proveitoso, pois o ponto de vista dos cegos nas palavras deles é mais importante do que a opinião de autores sobre eles. (M.)

[...] Esse último texto ressalta que nenhum vidente (por mais estudioso que seja, sobre o assunto) consegue entender as necessidades de um cego como o próprio cego. Se voltarmos ao simples quebra-cabeşa da primeira aula vamos entender perfeitamente o por que. (J.)

O trecho de M. refere-se aos capítulos I e II de Camargo (2008), apontando que o melhor informante sobre as necessidades do cego é ele próprio. Essa visão vai ao encontro de diversos pesquisadores sobre o tema da deficiência visual, como Franco (2008, p. 13):

Igualmente, não há produção científica que fundamenta o trabalho com pessoas com deficiência visual, a partir de seu próprio referencial perceptivo. De acordo com Masini (1994b), a maioria dos trabalhos tem se concentrado em crianças com deficiência visual, procurando descrever o processo de desenvolvimento de crianças cegas congênitas e, principalmente, métodos de avaliação, diagnóstico e técnicas de ensino. Muitas dessas pesquisas parecem, entretanto, inadequadas por utilizarem padrões comparativos entre videntes e não videntes, com materiais de ensino apropriados apenas para crianças videntes.

Fica claro, no segundo trecho deste episódio, que a experiência de "tornar-se cego" marcou o discurso dos licenciandos, uma vez que, na primeira aula, eles tentaram montar um quebra-cabeça com os olhos vendados.

As ideias abaixo tratam da formação de professores para trabalhar com turmas inclusivas e deficientes visuais:

[...] O outro texto discutido fala do processo de formação de professores e consideramos essencial disciplinas de educação inclusiva na graduação, já que $81 \%$ das instituições de ensino de formação de professores não tem disciplinas voltadas para educação especial. Isso faz com que os profissionais que são jogados no mercado de trabalho não estejam preparados para cumprir a lei, que prevê classes heterogêneas. (M.)

[...] a importancia de um professor se aprofundar um pouco mais nesse assunto a fim de não agravar a doença por falta de informação, ou até mesmo a fim ajudar os pais a detectar a deficiência. (J.)

Notamos, neste episódio, duas preocupações diferentes sobre o mesmo tema. M. traz a questão da formação de professores baseada na legislação e J. aponta a necessidade de o profes- 
sor compreender a "doença”". O discurso de J. está impregnado, ainda, do preconceito e do senso comum relativo à deficiência visual. Como nós não sabemos a que doença ela está se referindo, inferimos que é a cegueira e fizemos a afirmação anterior. Entretanto, ela pode estar se referindo a fatores psicológicos e sociais que podem, sim, dependendo do relacionamento entre aluno e professor, dificultar a convivência social e aprendizagem dos alunos com tal deficiência. Afinal, como diz Vygotsky (1997), é na sociedade que a criança vai se identificar como um ser deficiente. Ou ainda, como afirma Franco (2008), apoiado em Amiralian (1986), Higino (1986), Amaral (1994), Bruns (1997) e Dall'Acqua (1997): “A deficiência apresenta-se como um fenômeno construído socialmente e, assim sendo, ser ou estar 'deficiente' é quase sempre relativo a outras pessoas que são consideradas sem 'deficiências"' (FRANCO, 2008, p. 1).

Aqui notamos o movimento de reflexão dos licenciandos acerca do que é ser cego:

[...] Nas duas dinâmicas entendi que o objetivo era nos sensibilizar das dificuldades sofridas por deficientes visuais. [...] tanto uma quanto a outra me fizeram refletir, mesmo que superficialmente, das dificuldades de um não vidente e a estar atenta a outros sentidos que não só a visão. (V.)

[...] em sala de aula fizemos algumas atividades a fim de nos colocarmos no lugar de uma pessoa com deficiência visual e sentirmos suas necessidades. $A$ atividade que mais me chamou a atenção foi quando tentamos montar um quebra-cabeça de olhos fechados, foi simplesmente impossivel, só conseguimos sentir aonde terminava o quebra-cabeşa porque havia uma parte em baixo relevo. (J.)

Ambas tratam de experiências vividas em atividades de sala de aula. Podemos, inicialmente, afirmar que elas deram uma resposta ativa à proposta do exercício. Segundo Bakhtin (1997), essa compreensão responsiva ativa se baseia no papel do outro durante o diálogo: "Logo de início, o locutor espera deles uma reposta, uma compreensão responsiva ativa. Todo enunciado se elabora como que para ir ao encontro dessa resposta" (1997, p. 320).

Podemos, ainda, ressaltar que a atividade proposta em aula deixou marcas na construção de sua individualidade através da experiência: "A experiência é o que nos passa, o que nos acontece, o que nos toca. [...] Walter Benjamin, em um texto célebre, já observava a pobreza de experiências que caracteriza o nosso mundo. Nunca se passaram tantas coisas, mas a experiência é cada vez mais rara" (BONDÍA, 2002, p. 21).

O autor aprofunda mais adiante: "[...] o sujeito da experiência seria algo como um território de passagem, algo como uma superfície sensível que aquilo que acontece afeta de algum modo, produz alguns afetos, inscreve algumas marcas, deixa alguns vestígios, alguns efeitos" (BONDÍA, 2002, p. 24).

\section{Trabalhos finais}

Para os trabalhos finais, foi pedido que os alunos se dividissem em duplas e pensassem num tema curricular de física para montar um experimento, preferencialmente mensurável. Como as duplas, voluntariamente, escolheram temas diferentes entre si, eles não foram modificados. A dupla da qual participou M. escolheu o tema de reflexão e refração da luz, com 
ênfase em cores, V. trabalhou com ondas, priorizando a medida de comprimentos de onda, e J. escolheu o tema de termologia.

A ideia de M. e seu companheiro, para a montagem de seu experimento, envolveu um estudo aprofundado de como as cores estão presentes no dia-a-dia dos deficientes visuais. Além do estudo acerca das cores, a dupla montou um "olho humano" com os elementos importantes para entendimento de refração e reflexão, utilizando texturas diferentes para cada ponto de relevância para a percepção destes fenômenos. Entretanto, o experimento, com objetivo quantitativo, não foi realizado. A dupla alegou que, no momento de montar o experimento, sentiu muita dificuldade em pensar na medida e preferiu não abandonar o que já havia feito (estudo das cores para deficientes visuais e o olho humano). Vale ressaltar que esta dupla pensou prioritariamente nos deficientes visuais cegos e nos videntes para realizar o trabalho final, relegando os de baixa visão.

Figura 1. Imagens do trabalho final do grupo de M.
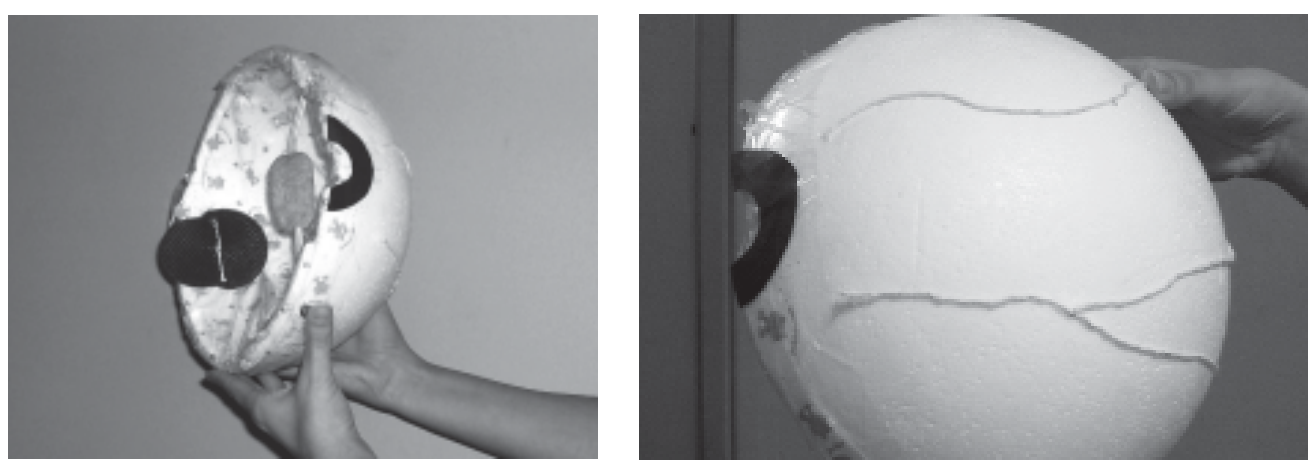

Fonte: Barbosa Lima e Castro (2009) ${ }^{5}$.

A dupla composta por V. escolheu ondas mecânicas. Ao apresentar o trabalho para os colegas, iniciou a atividade com o poema "A onda" de Manuel Bandeira, valorizando a interação dialógica com os colegas a partir de perguntas sobre o poema e ressaltando a importância de outras linguagens no ensino de física. Além do suporte teórico, a dupla conseguiu alcançar o objetivo do trabalho, montando um experimento mensurável para cegos, alunos de baixa visão - já que os componentes do experimento foram montados em cores diferentes para facilitar a visualização -, e, também, videntes. $\mathrm{O}$ experimento consistiu num quadro com uma escala bem definida, construída com palitos, e uma régua com a mesma escala a fim de que o comprimento de onda fosse medido.

\footnotetext{
${ }^{5}$ Imagens obtidas durante a disciplina "Ensino de Física e Inclusão Social” - ministrada no período de 2009/2 para alunos de licenciatura em Física.
} 
Figura 2. Imagem do trabalho final do grupo de V.

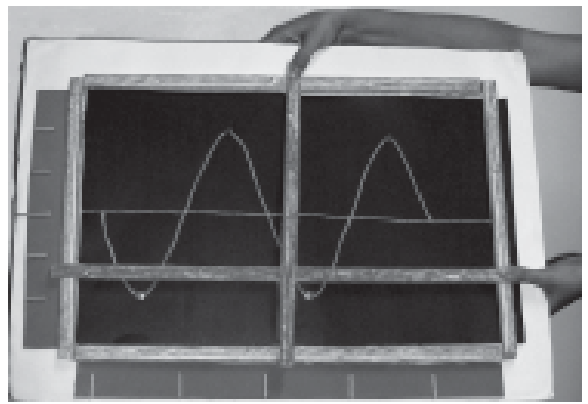

Fonte: Barbosa Lima e Castro (2009) ${ }^{6}$

Por último, J. utilizou, com sua dupla, a ideia de transmissão de calor. Para isto, construiu um suporte de alumínio com três pregos presos por parafina sólida. Na parte livre do suporte, a aluna acendia uma vela e, aos poucos, podia-se ouvir a queda de cada um dos pregos de acordo com sua posição em relação à extremidade que estava sendo aquecida. A dupla não conseguiu aproveitar a oportunidade de utilizar este experimento de forma quantitativa, não percebendo que o tempo de queda entre os pregos e o tempo da transmissão de calor pelo suporte poderia ser medido. Assim como no trabalho de M., os alunos de baixa visão foram negligenciados. Além disso, o experimento pode apresentar riscos aos deficientes visuais durante a locomoção na sala de aula.

Figura 3. Imagem do trabalho final do grupo de $\mathrm{J}$.

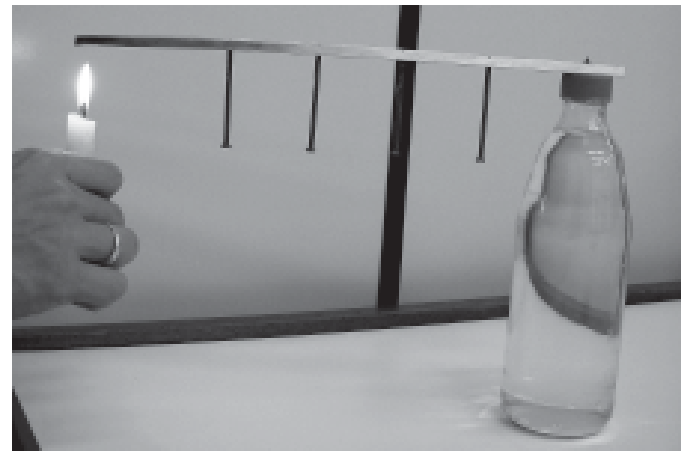

Fonte: Barbosa Lima e Castro (2009) ${ }^{7}$.

\footnotetext{
"Imagens obtidas durante a disciplina "Ensino de Física e Inclusão Social" - ministrada no período de 2009/2 para alunos de licenciatura em Física.

${ }^{7}$ Imagens obtidas durante a disciplina "Ensino de Física e Inclusão Social” - ministrada no período de 2009/2 para alunos de licenciatura em Física.
} 


\section{A avaliação da disciplina}

A avaliação da disciplina foi solicitada aos estudantes no último dia de aula. Consta de cinco perguntas objetivando conhecer a evolução de suas ideias durante o curso, sobre: a própria disciplina, a importância da disciplina em suas formações e a avaliação deles com relação às aulas ministradas.

1) $O$ que você entende por deficiência visual?

2) $\mathrm{O}$ que significa inclusão social?

3) $\mathrm{O}$ que a disciplina acrescentou em sua formação inicial?

4) $O$ que poderia ser mudado, retirado ou acrescentado nesta disciplina?

5) Você está preparado para trabalhar com uma turma inclusiva?

\section{Avaliação de M.}

M., ao escrever o que entende por deficiência visual, mescla, em seu discurso, a voz de um dos artigos trabalhados na disciplina, apontando uma visão mais social da deficiência: "Deficiência visual é uma condição que o individuo, por alguma raz̃ão, não possui um funcionamento mínimo do olho que permita levar uma vida normal, dentro dos padrões sociais pré-estabelecidos [...]" (grifo nosso). Notamos ainda que M. foi o único aluno a se preocupar em definir a deficiência de maneira técnica: "[...] No Brasil, é considerado deficiente visual uma pessoa que não enxerga a 1 metro de distância, o que uma pessoa considerada de visão normal enxergaria a 200 metros".

A ênfase dada, através da repetição, por M., ao diferenciar inclusão de integração, pode indicar a apropriação do discurso dos autores Pacheco, Eggertsdóttir e Marinósson (2007), bastante trabalhado no curso e sempre lembrado pelos próprios alunos em diversas aulas. Vale ressaltar que esse licenciando se assenhoreia do gênero discursivo da área em questão. M. atribuiu ao curso uma grande mudança na sua concepção em relação à Educação e em relação aos seus alunos videntes. Segundo ele, a disciplina "acrescentou até mesmo no contato com alunos "normais". Tenho mais sensibilidade ao tratar com as diferenças, mesmo a diferença entre os "normais". Além de introduzir um assunto que eu nem tinha noção que poderia ser tratado com a importância que é feito. A disciplina me permitiu expandir a minha visão de educação" (M.).

Ao escrever sobre sua formação, afirma que certamente não está preparado para trabalhar com uma turma inclusiva, mas percebe que tal formação lhe proporcionou uma "sensibilidade" maior com relação ao tema. Reflete sobre a possibilidade de trabalhar particularmente com um aluno deficiente, mas ainda não com a diversidade que pode ser encontrada em uma turma inclusiva.

\section{Avaliação de V.}

Surge, na resposta à primeira pergunta, a ideia de deficiência visual como, além de uma "debilidade biológica", um construto social (CAMARGO, 2008; LIRA; SCHLINDWEIN, 2008; FREIRE, 2005).

Notamos, na segunda resposta, que V. sai de seu discurso próprio e se apropria do gênero discursivo da área, usando, inclusive, um discurso secundário que é a definição de inclusão social. Isso pode ser compreendido ao se comparar tal resposta no questionário do 
primeiro encontro (discurso próprio) e na avaliação (discurso secundário), sendo as duas coerentes. Novamente, na terceira pergunta, ela assume o gênero de discurso da bibliografia quando traz a "voz" de autores trabalhados em aula para seu texto, mesclando-as à sua própria voz polifonia. Nesse caso, a ideia apontada por V. indica que aulas planejadas para turmas inclusivas estimulam o aprendizado de todos os alunos - videntes e deficientes visuais. Além disso, aponta que houve melhoria em sua formação devido aos novos conhecimentos construídos.

Ao avaliar a disciplina, V. não apresentou uma resposta objetiva, mas fez uma crítica aos colegas que não levaram o curso a sério. Finalmente, mesmo ressaltando novamente a melhoria em sua formação, V. ainda demonstrou insegurança. Ela afirmou que, para trabalhar com uma turma inclusiva, teria de recorrer aos conhecimentos de outros para caminhar. Vale ressaltar que somente a teoria não é suficiente para a formação de um professor inclusivo, mas é preciso que a prática, a metacognição e um primeiro "enfrentamento" façam parte de tal formação.

\section{Avaliação de J.}

Inicialmente, é necessário apontar que J. foi absolutamente sucinta em suas respostas, assim como o foi no questionário. Por isso, as respostas 1 e 4 não nos ofereceram condições de análise: a 1 foi respondida com uma simples definição e a 4 demonstrou que a aluna ficou satisfeita com o curso sem apontar críticas ou fazer sugestões. Tais respostas indicam um comportamento responsivo-passivo à maioria das interações verbais que aconteceu durante o curso.

Com relação à resposta da segunda questão, J. indicou que permanece com a dificuldade de diferenciar inclusão de integração, assim como percebido na sua resposta ao questionário. Vale lembrar que tal diferenciação foi exaustivamente debatida nas aulas da disciplina, o que pode demonstrar que J. foi refratária às atividades do curso que incluíram diversas bibliografias sobre o tema.

$\mathrm{Na}$ terceira resposta, conseguimos resgatar um pouco da polifonia, clara no discurso de V., acerca da questão da deficiência como algo socialmente construído. Vale a pena trazer a resposta de J. quando questionada sobre a importância da disciplina em sua formação: "Humanidade, me fez ver que a deficiência só é uma barreira para quem a 'enxerga' dessa forma".

Por fim, demonstrando medo, disse que encara o "mundo dos deficientes" como um mundo à parte, no qual ela ainda não entrou.

\section{Considerações finais}

O objetivo da pesquisa foi perceber as evoluções apontadas pelos futuros docentes frente ao tema de inclusão de alunos com Deficiência Visual (DV) a partir de suas próprias reflexões sobre os debates gerados em aula. Podemos enfatizar que tal objetivo foi alcançado. Para exemplificar, vamos trazer alguns aspectos importantes.

Podemos dizer que estes licenciandos pretendem tornar-se professores inclusivos, apesar de ainda demonstrarem receios de encontrar alunos deficientes visuais em suas futuras salas de aula. Alegam, para isso, a falta de experiência prática. 
Nesse sentido, notamos ainda que, em suas anotações nos diários de bordo, eles deixam claro a importância da disciplina em questão para suas próprias formações, o que ratifica nossa ideia de repensá-la e reestruturá-la com o objetivo de que ela se torne uma disciplina obrigatória.

As leituras e discussões dos textos foram apontadas de forma positiva nos discursos dos alunos. Podemos, inclusive, reconhecer as várias vozes de seus autores nos enunciados dos licenciandos. Ainda nesta perspectiva, podemos inferir a apropriação do gênero discursivo da área de ensino de física para deficientes visuais pelos estudantes.

Por fim, é importante destacar que os trabalhos finais ainda estão longe de alcançar o que desejamos. A proposta de experimentos mensuráveis por cegos, alunos de baixa visão e videntes conjuntamente não foi cumprida de maneira criativa pela única aluna que o fez. E os demais nos sugerem que há uma impossibilidade na elaboração, nesse tipo de experimento, e na execução de medidas por esses alunos, ficando, ainda, assim restritos a experimentos demonstrativos.

\section{Referências}

AMARAL, L. A. Pensar a diferença: deficiência. Brasília: CORDE, 1994.

AMIRALIAN, M. L. T. M. Psicologia do excepcional. São Paulo: EPU, 1986.

ANJOS, H. P. dos; ANDRADE, E. P. de; PEREIRA, M. R. A inclusão escolar do ponto de vista dos professores: o processo de constituição de um discurso. Revista Brasileira de Educação, Rio de Janeiro, v. 14, n. 40, p. 116-129, jan./abr. 2009.

BAKHTIN, M. Estética da criação verbal. 2. ed. São Paulo: Martins Fontes, 1997.

BONDÍA, J. L. Notas sobre a experiência e o saber de experiência. Revista Brasileira de Educação, Rio de Janeiro, n. 19, p. 20-28, jan-abr. 2002. Disponível em: <http:// www.anped.org.br/rbe/rbedigital/RBDE19/

RBDE19_04_JORGE_LARROSA_BONDIA.pdf>. Acesso em: 23 mar. 2010.

BRAIT, B. Análise e teoria do discurso IN: Brait, B. (Org.) Bakhtin: outros conceitoschave, São Paulo: Contexto, 2006.

BRASIL. Lei 9.394, de 20 de dezembro de 1996. Estabelece as diretrizes e bases da educação nacional. Diário Oficial da União, Brasília, DF, 23 dez. 1996. p. 27.833.

BRUNS, M. A. T. Deficiência visual e educação sexual: a trajetória dos preconceitos ontem e hoje. Benjamin Constant, Ano 3, (7), p. 9 - 16. Rio de Janeiro: IBCENTRO/ MEC, 1997.

CAMARGO, E. P. de; NARDI, R. Planejamento de atividades de ensino de física para alunos com deficiência visual: dificuldades e alternativas. Revista Eletrónica de Enseñanza de las Ciencias, v. 6, n. 2, p. 378-401, 2007. Disponível em: <http:// www.saum.uvigo.es/reec/volumenes/volumen6/ART9_Vol6_N2.pdf >. Acesso em: 15 jul. 2007 
Formação inicial de professores de Física: ...

CAMARGO, E. P. de; NARDI, R. Ensino de física e deficiência visual: dez anos de investigações no Brasil. São Paulo: Plêiade; FAPESP, 2008.

CASTRO, G. F. de. A construção da (auto) imagem do professor: os saberes explícitos e implícitos nos discursos de professores de física sobre a prática docente e a formação inicial. 2009. 128f. Dissertação (Mestrado em Educação) - Universidade Federal Fluminense, Niterói, 2009.

DALL'ACQUA, M. J. C. Estimulação da visão subnormal de uma criança no ambiente escolar: um estudo de caso. TESE (Doutorado em Educação). 212 fl. Universidade Federal de São Carlos, São Carlos, 1997.

DECLARAÇÃO de Salamanca sobre princípios, políticas e práticas na área das necessidades educativas especiais. In: CONFERÊNCIA MUNDIAL DE EDUCAÇÃO ESPECIAL, 1994, Salamanca. Salamanca: Unesco, 1994. Disponível em: <http:// portal.mec.gov.br/seesp/arquivos/pdf/salamanca.pdf >. Acesso em: 10 maio 2007.

FRANCO, J. R. Deficiência visual: entre mitos e fatos. In: CONGRESSO BRASILEIRO DE EDUCAÇÃO ESPECIAL, 3., 2008. Curso. São Carlos: Universidade Federal de São Carlos, 2008. (Anotações).

FREIRE, I. M. A experiência com a cegueira. Benjamin Constant, Rio de Janeiro, ano 11, n. 31, ago. 2005. Disponível em: <http://www.ibc.gov.br/?catid=4\&itemid=10030>. Acesso em: 23 nov. 2009.

HIGINO, V. P. De criança padrão a adulto divergente - estudos sobre o comportamento do deficiente visual. DISSERTAÇÃO (Mestrado em Educação) 185 fl. Centro de Educação e Ciências Humanas, Universidade Federal de São Carlos, São Carlos: 1986.

LAPLANE, A. L. F. de; BATISTA, C. G. Ver, não ver e aprender: a participação de crianças com baixa visão e cegueira na escola. Cadernos CEDES, Campinas, v. 28, n. 75, p. 209227, mai-ago 2008.

LIRA, M. C. F. de; SCHLINDWEIN, L. M. A pessoa cega e a inclusão: um olhar a partir da psicologia histórico cultural. Cadernos CEDES, Campinas, v. 28, n. 75, p. 171-190, maiago 2008.

MARASCHIN, C. Pesquisar e intervir. Psicologia \& Sociedade, Belo Horizonte, v. 16, n. 1, p. 98-107, 2004. (Número especial). Disponível em <http://www.scielo.br/ scielo.php?script $=$ sci_pdf\&pid $=$ S0102-71822004000100008\&lng $=$ pt\&nrm $=$ iso\&tlng $=$ pt $>$. Acesso em: 30 maio 2009.

MINAYO, M. C. S. Ciência, técnica e arte: o desafio da pesquisa social. In: MINAYO, M. C. S. (Org). Pesquisa social: teoria, método e criatividade. Petrópolis: Vozes, 1994. p. 9-29.

PACHECO, J.; EGGERTSDÓTTIR, R.; MARINÓSSON, G. L. Caminhos para a inclusão: um guia para o aprimoramento da equipe escolar. Porto Alegre: Artmed, 2007. PÉREZ GÓMEZ, A. I., Compreender o ensino na escola: modelos metodológicos de 
Lima, M. C. B.; Castro, G. F.

investigação educativa. In: PÉREZ GÓMEZ, A. I.; SACRISTÁN, J. G. Compreender e transformar o ensino. 4. ed. Porto Alegre: Artmed, 1998. p. 99-117.

SILVA, F. F. da. Quais as dificuldades encontradas pelos professores de física para trabalharem com alunos com necessidades especiais visuais? 2009. $60 \mathrm{f}$. Trabalho de conclusão de curso (Licenciatura em Física) - Instituto de Física Armando Dias Tavares, Universidade do Estado do Rio de Janeiro, Rio de Janeiro, 2009.

VYGOTSKY, L. S. Obras escogidas: fundamentos de defectologia. Madrid: Visor, 1997. Tomo 5.

ZABALZA, M. A. Os diários de classe dos professores. Pátio: revista pedagógica, Porto Alegre, v. 6, n. 22, p.15-20, jul./ago, 2002.

Artigo recebido em 24/02/2011. Aceito em 22/08/2011. 